\title{
A CIDADE CRIATIVA E SUAS EXPERIÊNCIAS: O CASO MISSISSIPPI DELTA BLUES FESTIVAL DE CAXIAS DO SUL
}

Cristina Biazus Danieleski

Universidade do Vale do Rio dos Sinos

crisdanieleski@gmail.com

Fabricio Farias Tarouco

Universidade do Vale do Rio dos Sinos

ftarouco@unisinos.br

Resumo: Uma cidade criativa possui como principais características a inovação, a conexão, a cultura e o design. Quando uma pessoa vivencia uma urbe que tenha a presença destes elementos, ela tem a possibilidade de experimentar uma cidade criativa. Eventos são formas de interação com ambientes criativos e possibilitam o desenvolvimento de um sistema inovador. Este artigo investiga as características de um evento musical, o Mississippi Delta Blues Festival que ocorre anualmente na cidade gaúcha de Caxias do Sul - RS, e analisa sua colaboração e relevância na concepção de uma cidade criativa, tendo como base de estudo dois eventos semelhantes, o Festival de Blues de Chicago e o Rio das Ostras Jazz e Blues.

Palavras-chave: Cidades Criativas; Experiências; Eventos; Mississippi Delta Blues Festival. 


\section{INTRODUÇÃO}

O conceito de criatividade, segundo definição do dicionário AURÉLIO (2015), é a capacidade de criar e inventar, bem como a qualidade de quem tem ideias originais, estando, portanto, diretamente relacionada com o ser humano. Fazendo a ligação com o contexto das cidades, pode-se dizer, então, que cidade criativa é uma urbe que possui a capacidade ou aptidão de resolver problemas urbanos através de criações e/ou invenções. Muito além desta rápida conexão, o conceito de cidade criativa abrange um conjunto de características e relações muito mais profundas. É um conceito em formação onde algumas formas de entendimento podem acontecer em função da abordagem do tema.

Um dos pilares de uma cidade criativa é o fato de estar sempre em transformação (REIS, 2010, p. 23), em um entendimento próximo ao de KAGEYAMA sobre o tema (KAGEYAMA, 2011, p. 55), que afirma que a cidade criativa é um sentimento de que algo está acontecendo, um sentimento de movimento e energia. Além disso, uma cidade criativa busca a conexão nos mais diversos sentidos e âmbitos, e se converte em um polo de atrações.

Dos elementos formadores da cidade, o espaço público é fundamental para dar suporte à cidade criativa e suas atividades, dentre elas, os aspectos culturais (REIS, 2010, p.24). Ademais, cidade criativa está diretamente associada à população que à vive. STRICKLAND (2011, p. 51), afirma que "a cidade se torna um lugar criativo a partir de quem vive, trabalha, constrói, reza e se diverte".

Neste contexto de pessoas, surge o conceito de experiência, que é definida por qualquer conhecimento obtido através dos sentidos. Nesta ideia, a palavra "experimentar" refere-se à sentir. Experiência da cidade, então, pode ser entendida como o conhecimento da cidade através dos sentidos, contexto em que o design oferece inúmeras contribuições.

Eventos são formas de proporcionar experiências e sensações da cidade às pessoas. Além disso, são de grande importância para a valorização da imagem das cidades e impactam na cultura e na economia. Conforme VERHAGEN (2011, p. 113), eventos recorrentes ajudam a consolidar o nome de uma cidade e podem torná-la muito criativa através da criação de novas atividades.

Este artigo introduz a análise de eventos culturais e sua importância para uma cidade criativa, tendo como objeto central um evento musical específico, o Mississippi Delta Blues Festival (MDBF), que ocorre anualmente na cidade gaúcha de Caxias do Sul. Para isso, será resgatado um breve histórico do termo "cidade criativa" e serão analisadas suas principais características e desdobramentos. A questão da "experiência" será analisada a partir de dois casos semelhantes, o Festival de Blues de Chicago e o Rio das Ostras Jazz e Blues Festival, compartilhando também uma descrição do evento MDBF e sua importância, e de outras festas similares, no contexto de cidades criativas.

\section{CIDADE CRIATIVA}

A ideia de cidade criativa já tem um tempo e remonta aos anos de 1980. Segundo CHARLES LANDRY (apud REIS; KAGEYAMA, 2011, p. 7), o início do 
pensamento sobre o assunto foi através do objetivo da comunidade artística em justificar seu valor econômico, inicialmente nos Estados Unidos, no Reino Unido e na Austrália, tendo posteriormente se espalhado por toda a Europa. Isto gerou um grande movimento em torno dos profissionais de áreas criativas que buscavam demonstrar sua importância para a economia das cidades. Ao longo dos anos 1990, o tema passou a ser discutido em conferências internacionais e ganhou ainda mais espaço com importantes publicações sobre o tema.

Conforme LANDRY (apud REIS; KAGEYAMA, 2011, p. 10), inicialmente, o conceito de "cidade criativa" foi considerado o de um lugar onde os artistas desempenhavam um papel central e onde a imaginação definia os traços e o espírito da cidade. Com o tempo, indústrias criativas, classes criativas, comunidades de pesquisa e nômades do conhecimento passaram a ter grande importância neste contexto. Além disso, segundo REIS (2010, p.23), considera análises sobre as dinâmicas das cidades, suas relações e estruturas passaram a ser aspectos observados para a identificação e o entendimento da criatividade como um elemento propulsor de diversos benefícios, como sociais, culturais e econômicos.

Entende-se que ainda não há características definitivas para o conceito de cidade criativa, mas há alguns elementos comuns à diversos autores e pesquisadores deste tema. Numa síntese, REIS (2010, p. 24) afirma que "para a maioria dos autores, a cidade criativa tem uma aura sensorial", além de buscar a superação de problemas das urbes e trabalhar com o fato da cidade estar em constante mudança.

Para que o conceito de cidade criativa possa ser colocado em ação, o planejamento à longo prazo é de extrema importância com objetivos claros e alcançáveis. Neste contexto, REIS (REIS; KAGEYAMA, 2011, p. 27) defende que "o agente catalisador de mudanças pode ser o governo (especialmente o municipal, mais próximo da sociedade), uma empresa privada ou uma organização da sociedade civil". Estes são os agentes possuidores de capacidade e responsabilidade para o início de transformações que podem abranger toda a sociedade quando bem esclarecidos e objetivados, pois, a cidade criativa estimula a participação à cidade. Segundo LANDRY (apud REIS; KAGEYAMA, 2011, p. 14), "uma cidade criativa procura identificar, nutrir, atrair e manter talentos, de modo a conseguir mobilizar ideias, talentos e empresas criativas". Isso requer esclarecimento, comprometimento e responsabilidade dos agentes envolvidos no intuito de cativarem e educarem as pessoas da sociedade para esta forma de pensar a cidade para que se tornem agentes modificadores do seu meio e contribuam com as mudanças e inovações da urbe.

\section{AS EXPERIÊNCIAS NA CIDADE CRIATIVA}

Ainda que as cidades criativas estejam sempre em transformação, os autores já citados convergem que há três características necessárias e complementares para que urbes possam ser definidas como cidades criativas: inovação, conexões e cultura. Nesse entendimento, inovação diz respeito à criação de modelos de forma criativa visando benefícios à sociedade; conexões são as diversas relações da cidade que a tornam um sistema integrando: espaço urbano, setores público, privado e a sociedade civil, a situação da cidade na questão local, regional e global, as classes sociais e as conexões; A cultura, no contexto de cidade criativa, diz respeito ao reconhecimento 
desta como contribuição econômica, de qualidade de vida, de participação de quem compõe a cidade e de possibilidade para criação de novas alternativas. Estes três fatores (inovação, conexões e cultura), são características enredadas no âmbito de cidade criativa (REIS, 2010, p. 24), que busca a surpresa e o estímulo à resolução de problemas de forma inventiva.

Experienciar uma cidade criativa pode ser entendida como o ato de vivenciar uma cidade onde existam os três aspectos citados anteriormente. Assim, eventos e festivais são formas de proporcionar às pessoas vivências diferentes do seu cotidiano, sabendo que festivais temáticos buscam a identificação com um determinado tipo de público e possibilitam a criação de uma imagem sobre o local onde ocorre.

Eventos musicais, como os festivais de blues, são exemplos desta busca pela formação de uma imagem projetada. O estilo musical de blues é originário da região sul dos Estados Unidos por volta dos anos 1900 e se expandiu pelo país chegando à Chicago nos idos de 1940. O som, popularizado pelos negros americanos, surgiu baseado nos cantos religiosos de africanos e descendentes de escravos e expressava as angústias e os sofrimentos do povo, se tornando de fato uma cultura popular nos Estados Unidos através do advento da música eletrônica explorada também em Chicago (MSDELTA, 2015a).

O Festival de Blues de Chicago ocorre anualmente desde o ano de 1984 e é considerado o maior festival do mundo do seu estilo. $O$ evento gratuito acontece em um parque da cidade, no anfiteatro aberto conhecido como Petrillo Music Shell e caracteriza-se por ser um evento diurno que se estende até a noite, com atrações musicais ao longo de três dias (CHICAGO, 2015a). O festival acontece sempre no mês de junho, mais precisamente na entrada do verão no hemisfério norte, e cada edição possui um tema, geralmente, uma homenagem à algum músico influente do estilo, tendo como principal atração os shows em si, apresentando artistas locais, regionais e internacionais em três palcos simultâneos. Na figura a seguir, observa-se um dos palcos do evento (CHICAGO, 2015b).

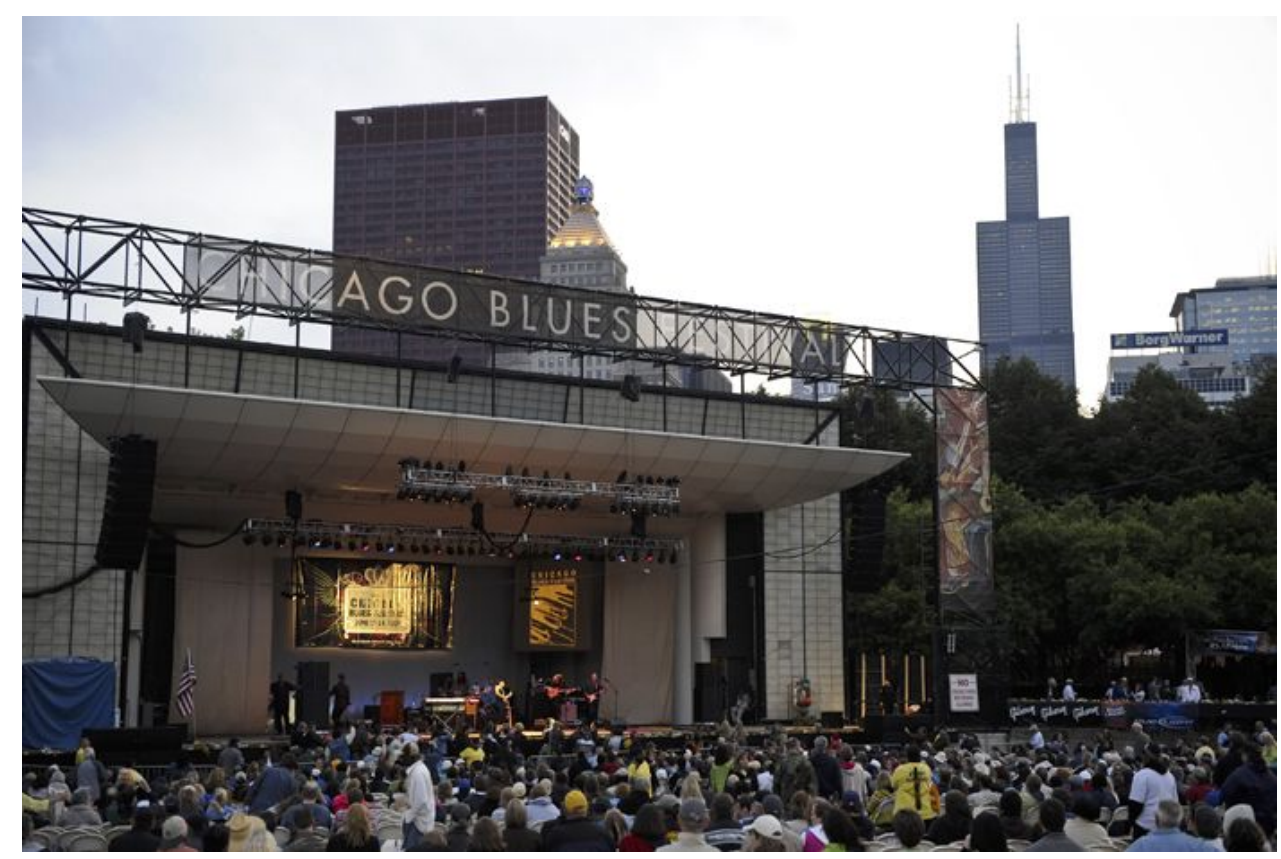

Figura 1: Imagem de um palco do Festival de Blues de Chicago. Fonte: CHICAGO, 2015c 
O festival contribui para o fortalecimento da imagem da cidade em relação ao estilo de música, que se fortaleceu nos anos 60 , e é utilizado como uma ferramenta educacional. O evento celebra a música que retrata a liberdade da escravidão e a capacidade de expressão, e este cunho social é abordado nas escolas da cidade como forma de entendimento da história e da tradição do blues. Além disso, antes do festival, músicos profissionais participam de workshops em escolas ensinando sobre a música e os instrumentos e ensaiando com os alunos para que estes participem de apresentações durante o evento. Este programa visa o fortalecimento curricular em relação à temas como artes, humanidades e ciências, além de proporcionar novas experiências de aprendizagem aos alunos (CHICAGO, 2015d).

No Brasil, há diversos festivais semelhantes espalhados pelo país como, por exemplo, o Guriri Jazz e Blues, que acontece na llha de Guriri, bem como, o evento Internacional de Blues e Cervejas Artesanais em Vitória, ambos no Espírito Santo, o Canoa Blues em Fortaleza, Ceará, o Ibitipoca Blues na serra de Ibitipoca em Minas Gerais e o Rio das Ostras Jazz e Blues que ocorre no balneário de Rio das Ostras no Rio de Janeiro.

O Rio das Ostras Jazz e Blues acontece desde o ano de 2003 e teve início através do Projeto Rio das Ostras Instrumental com apresentações mensais nos anos de 2001 e 2002 em algumas praias do balneário de Rio das Ostras. O projeto cresceu e se tornou um festival em função do grande interesse da população local e de turistas, despertando o olhar dos gestores públicos locais para a possibilidade de criação de um evento maior e melhor estruturado (OSTRAS, 2015a).

Inicialmente, o evento ocorria em pequenos palcos em praias distintas do balneário, como Costazul, Praia da Tartaruga, Lagoa de Iriry e na praia do Cemitério. Na sua terceira edição, em 2005, foi criada a Cidade do Jazz e do Blues na praia de Costazul com estrutura formada por um palco principal, observado na Figura 2, espaço para exposições, praça de alimentação, pontos de apoio e pontos de venda de produtos específicos do festival. Através da ampliação da proposta, aliado à pequenos palcos simultâneos em outras praias, o festival consolidou sua posição de destaque no cenário nacional (OSTRAS, 2015a).

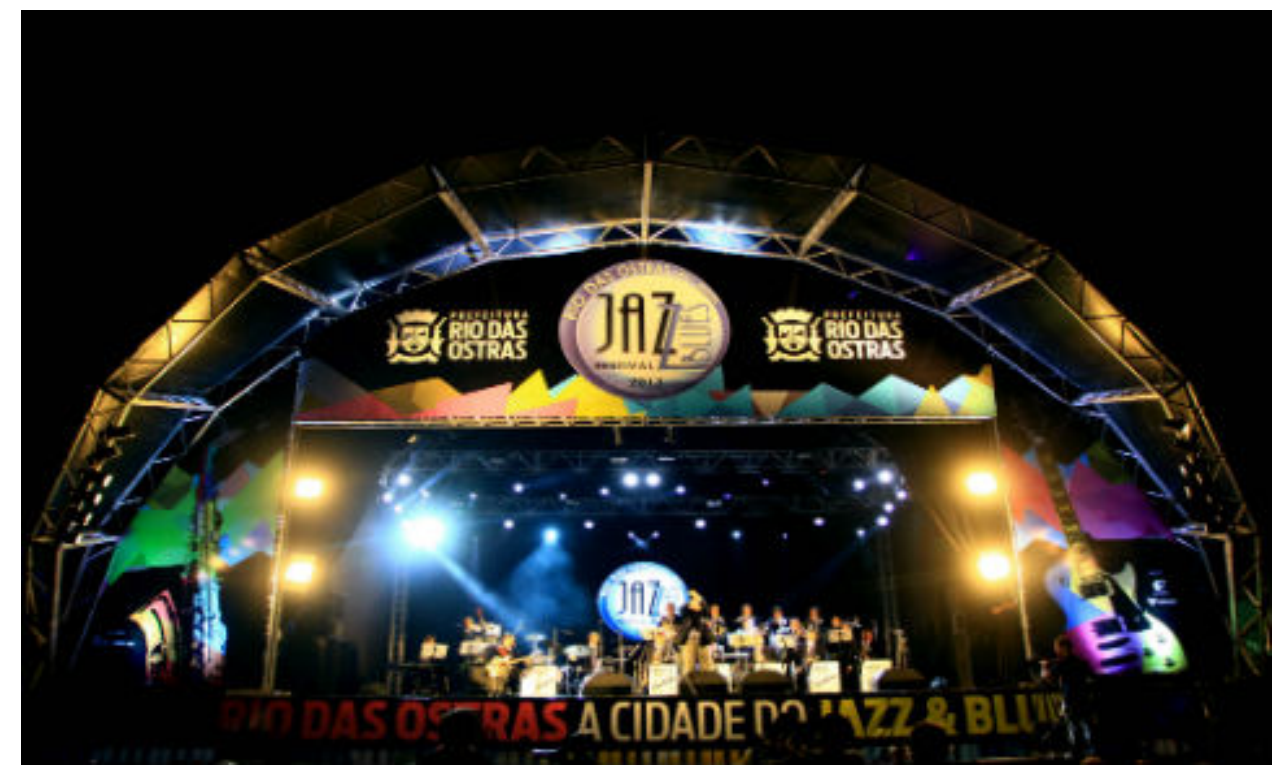

Figura 2: Palco da Cidade do Jazz e do Blues em Costazul. Fonte: OSTRAS, 2015b. 
Atualmente, o festival conta com três palcos principais: o Iriry, o Costazul e o da praça São Pedro. O palco Iriry é um anfiteatro ao ar livre cercado por vegetação nativa e encontra-se em uma unidade de conservação que abriga a Lagoa de Iriry. No Costazul encontra-se o palco principal do evento, na Cidade do Jazz e Blues, e recebe as maiores atrações e o maior público. Na praça de São Pedro encontra-se uma concha acústica, Figura 3, e em seu entorno há áreas com playgrounds, feiras de artesanato e quiosques com gastronomia local (OSTRAS, 2015b).

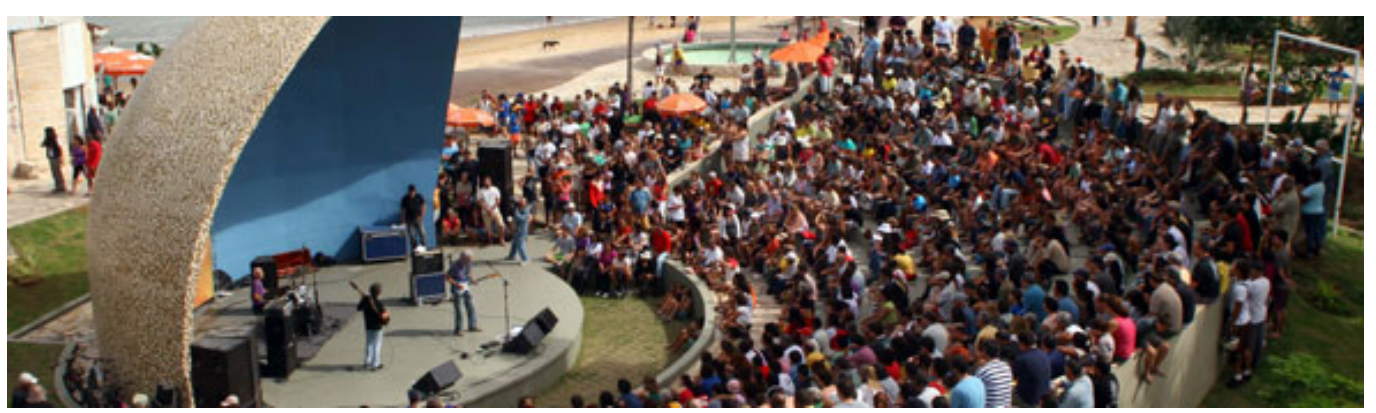

Figura 3: Concha acústica da praça de São Pedro. Fonte: OSTRAS, $2015 \mathrm{~b}$.

O evento acontece ao longo de 04 dias no mês de agosto, com apresentações diurnas e noturnas nos 3 palcos, além de rápidas apresentações em pontos turísticos do balneário de Rio das Ostras. As edições contam com atrações nacionais e internacionais quem podem ser assistidas em tempo real pela web através do portal da Prefeitura. Além disso, o festival conta com projetos idealizados e realizados por alunos de Produção Cultural da Universidade Federal Fluminense. O Rio das Ostras Jazz e Blues é realizado através de patrocínio por meio da Lei de Incentivo da Secretaria Estadual do Rio de Janeiro e apoio da prefeitura Municipal de Rio das Ostras, por meio da Secretaria de Turismo.

O evento anual é de grande importância para a econômica da cidade. Segundo pesquisa realizada em 2004 pela Fundação Getúlio Vargas (FGV/RJ), mais de 11 milhões de reais foram injetados na economia do município durante o período do festival (OSTRAS, 2015c). Este dado, exemplifica a importância de festivais semelhantes em outras cidades, como o caso do Mississippi Delta Blues Festival.

\section{MISSISSIPPI DELTA BLUES FESTIVAL}

Como vem sendo interpretado, uma cidade criativa é aquela que se beneficia de sua importância histórica e une grupos, afeta economias de escalas de suprimentos, de informações, troca de ideias, concentrações de capital, proximidade de emprego e oportunidades de trabalho (STRICKLAND, 2011, p. 51). Além disso, conforme PARDO (2011, p. 85), a cidade criativa é uma área urbana voltada à inovação e à cultura, onde inovação é interpretada pelo resultado da implementação de critérios de visibilidade para a criatividade, gerando valores de mudança, melhoria e progresso em todas as atividades econômicas, sociais e culturais.

Sendo assim, eventos musicais buscam inovação, união de diferentes pessoas, desenvolvimento cultural e econômico e possibilitam à população experienciar as cidades. É o caso do festival Mississippi Delta Blues, consolidado no cenário local e regional da cidade de Caxias do Sul - RS, que tem como ponto de partida um bar de 
mesmo nome, o Mississippi Delta Blues Bar. Este bar foi inaugurado no ano de 2006 e tem como inspiração a cultura do sul dos Estados Unidos, como bares de beira de estrada, e busca ofertar shows de blues e southern rock e comidas típicas da região aliados à uma ambientação característica (MSDELTA, 2015b).

Shows com artistas de referência da área eram realizados no bar, ilustrado na Figura 4, mas com público limitado em função do espaço físico. Com o objetivo de atender mais pessoas e proporcionar um encontro entre os artistas do estilo, inspirado no Chicago Blues Festival, surgiu a ideia do festival no ano de 2008, que contou com 5 palcos simultâneos em sua primeira edição. Inicialmente planejado como um evento local, ao longo das edições o festival ganhou notoriedade regional e nacional e no ano de 2014 foi considerado o maior festival de blues do continente americano fora dos Estados Unidos (MDBF, 2015a).

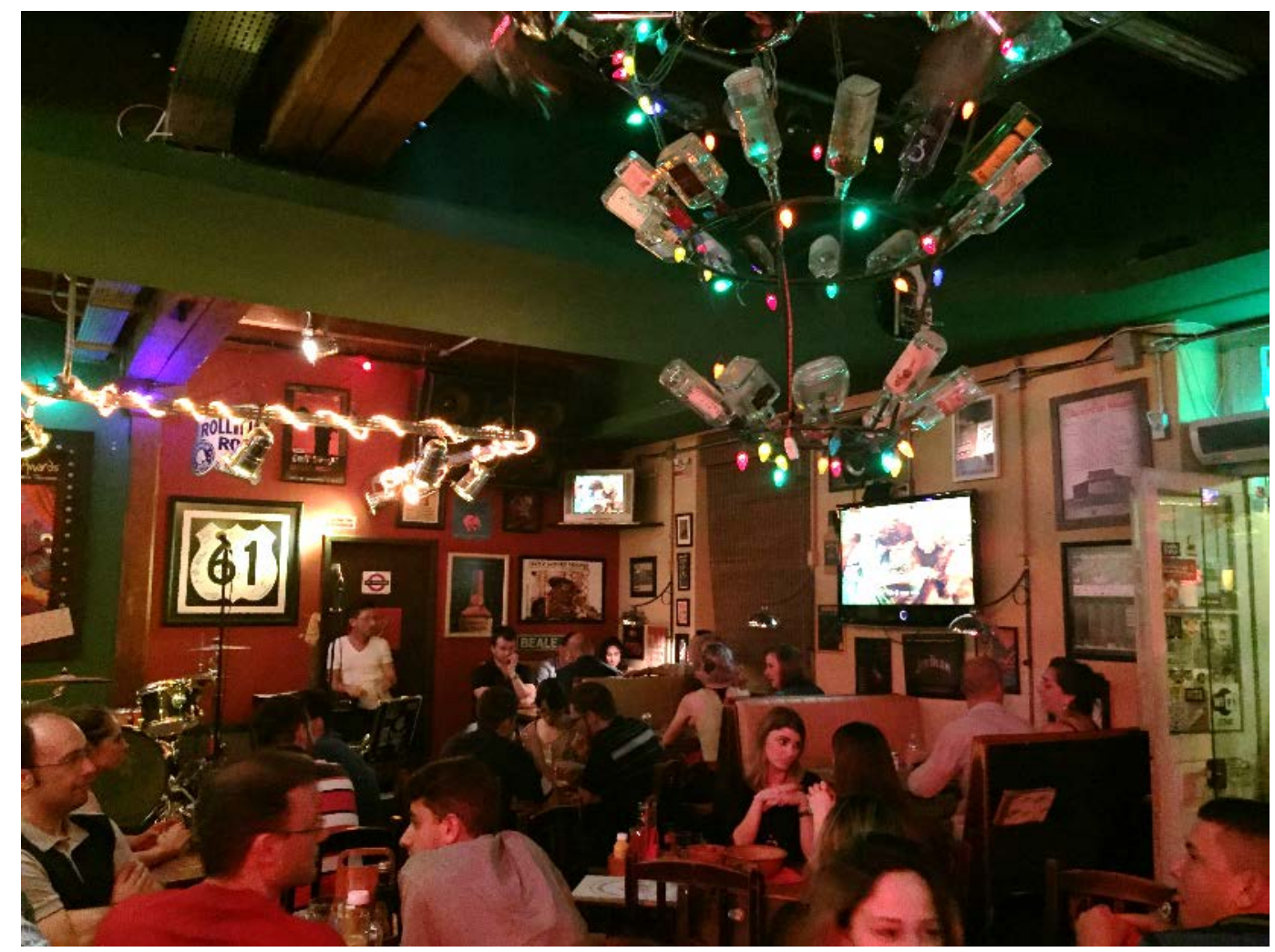

Figura 4: Mississippi Delta Blues Bar. Fonte: autor.

Este evento ocorre nos arredores da antiga estação férrea da cidade, ilustrada na Figura 5, caracterizado como forte cenário cultural e de lazer de Caxias do Sul - RS. Após revitalizações da região, a área passou a ser conhecida como Largo da Estação e passou a abrigar a Secretaria Municipal da Cultura, a Biblioteca Parque da Estação, bem como salas comerciais, confeitarias, restaurantes, casas noturnas e bares das mais variadas tipologias (FESUPPO, 2015). 


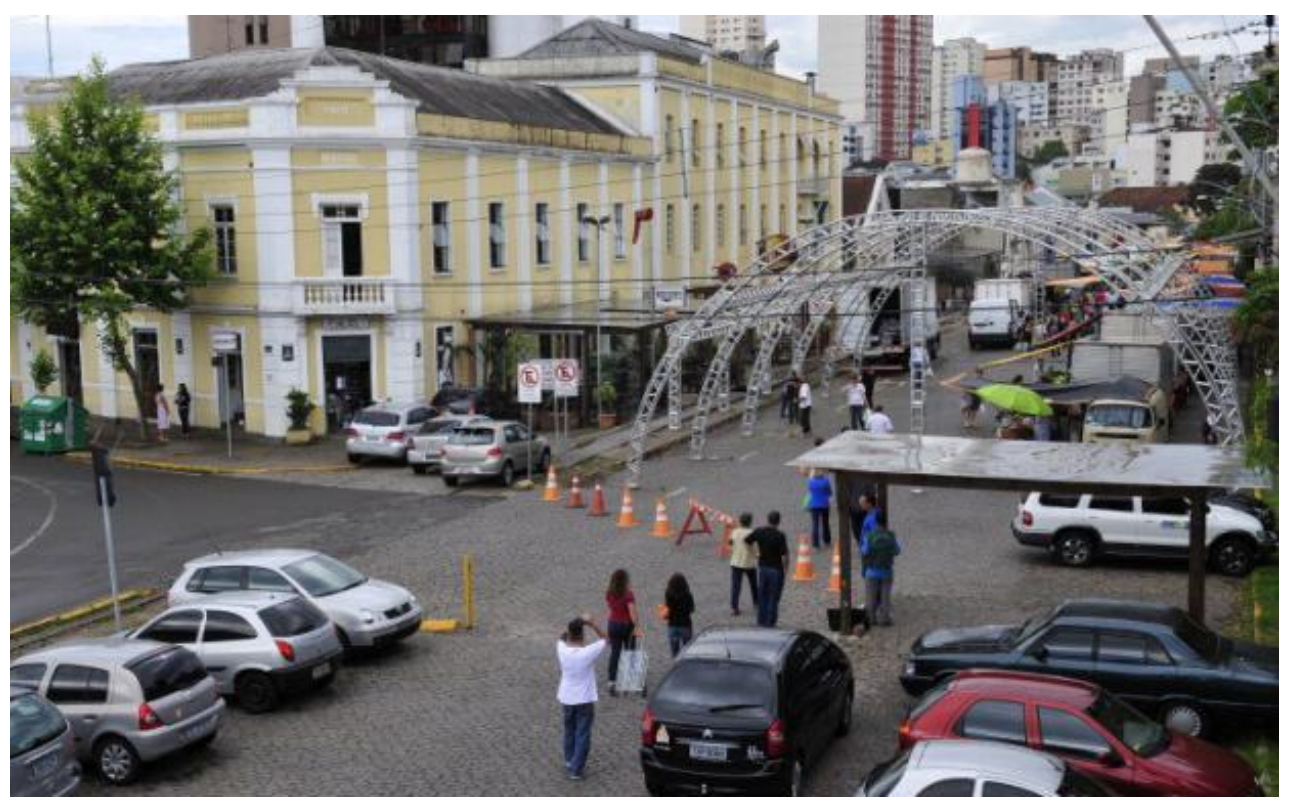

Figura 5: Montagem da estrutura do MDBF no Largo da Estação Férrea de Caxias do Sul. Fonte: (FESUPPO, 2015).

Planejado como um evento noturno, o festival que ocorre sempre no final do mês de novembro, busca conectar música, cultura e experiências sensoriais através de shows, workshops, gastronomia, diversão e arte. Nas apresentações (ver Figura 6), artistas locais, nacionais e internacionais fazem shows simultâneos nos variados palcos do festival. Além disso, são ofertados workshops gratuitos para público de todas as idades sobre música e instrumentos do blues.

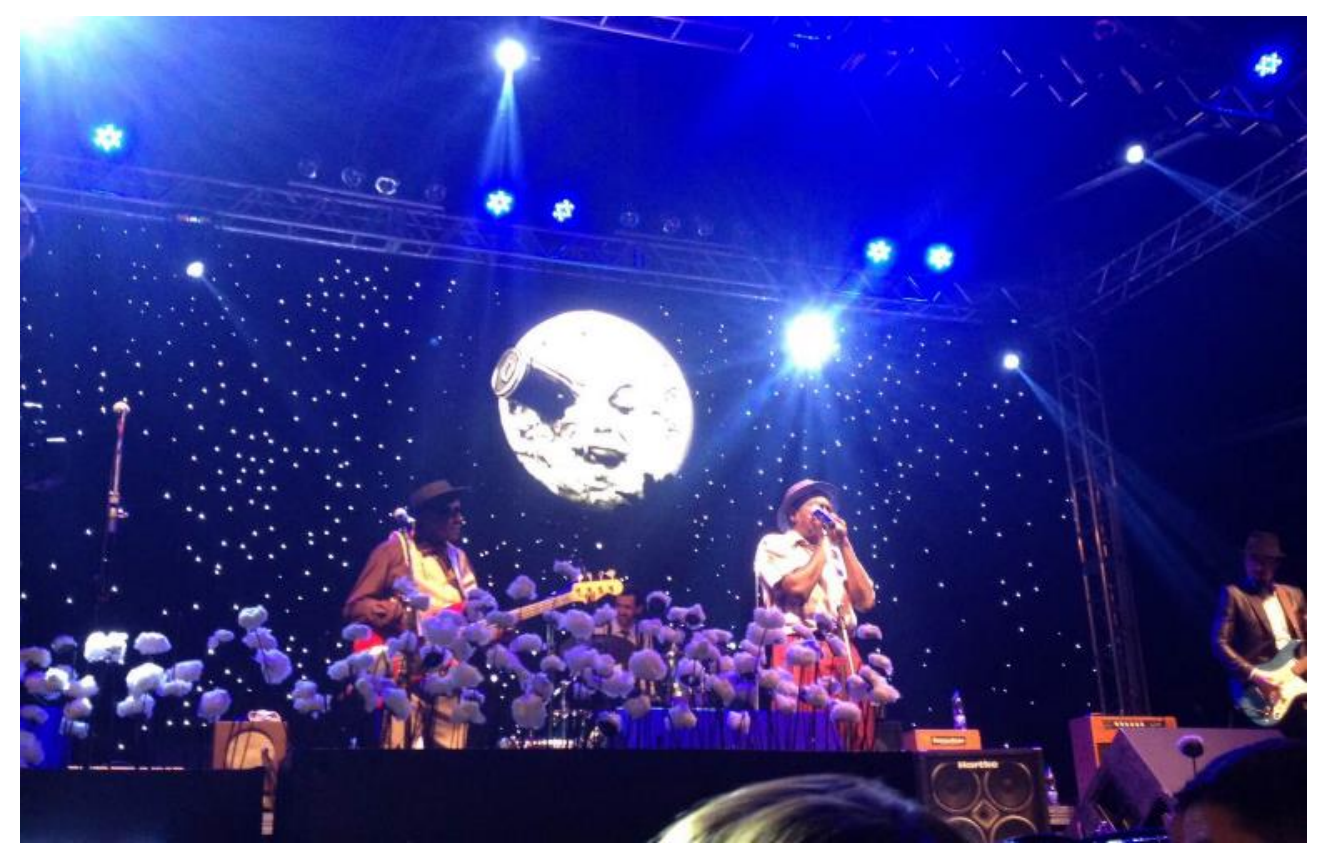

Figura 6: Palco principal do Mississippi Delta Blues Festival no ano de 2015. Fonte: autor.

$\mathrm{Na}$ questão de gastronomia, inicialmente o festival oferecia comidas típicas do sul dos Estados Unidos disponíveis no bar Mississippi Delta Blues. Com o crescimento do evento, outras experiências gastronômicas foram sendo proporcionadas como food trucks locais encontrados no espaço Food Park Stage e cervejas e chopps artesanais de 
fabricantes da cidade e da região localizados no espaço denominado Beer Square (MDBF, 2015b).

Algumas edições do evento ofereceram pequenos parques de diversão como forma de entretenimento extra, além da interatividade possível através de espaços com painéis para escrever e desenhar, ilustrada na Figura 7. Busca-se ainda, a relação com a história da cultura do blues através de diversas formas, como mostras fotográficas e pequenas apresentações de danças características (Figura 8). Promovendo ainda mais a relação com a arte, a edição de 2015 contou o espaço Feet Off The Ground onde recebeu a Cia Municipal de Dança de Caxias do Sul com rápidas apresentações de coreografias desenvolvidas exclusivamente para o festival (MDBF, 2015b).

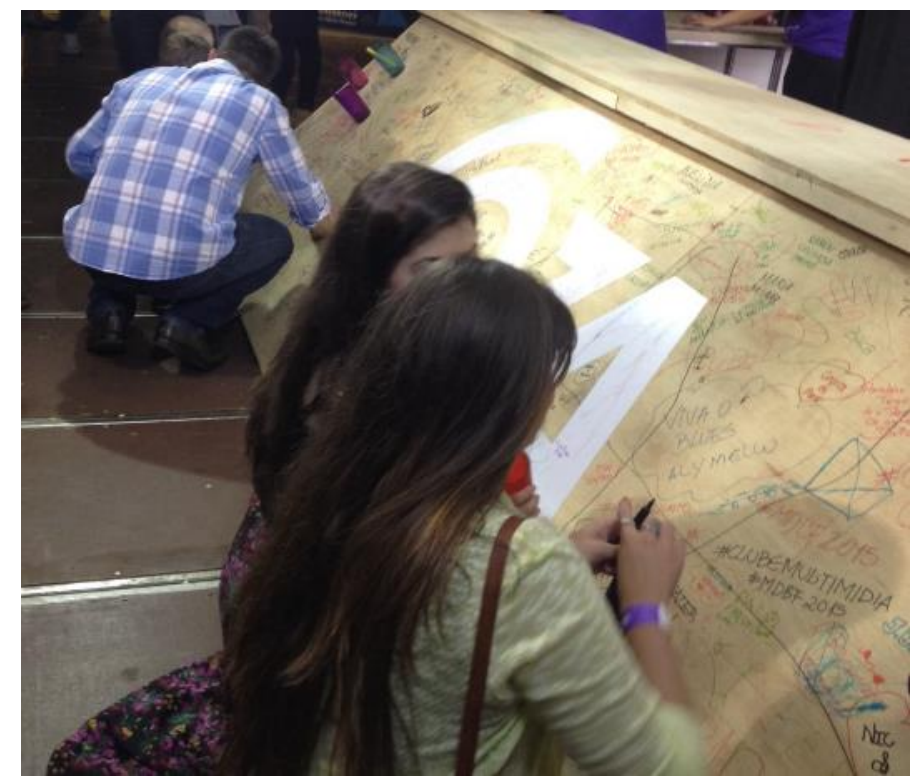

Figura 7: Painel interativo do festival no ano de 2015. Fonte: autor.

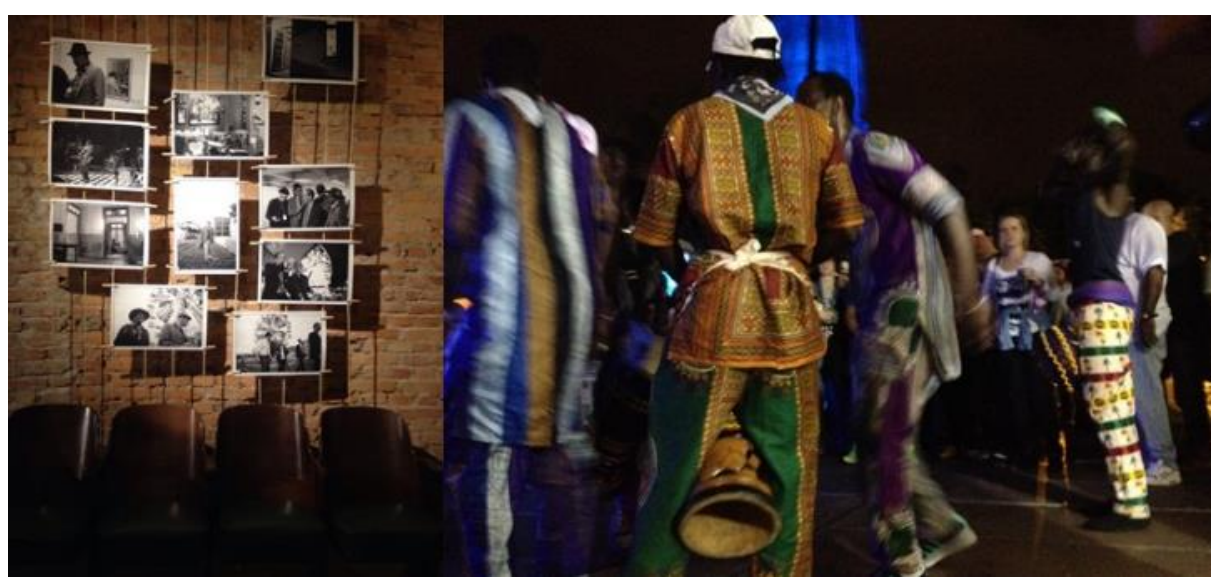

Figura 8: Mostra fotográfica e apresentação característica do estilo blues no Mississippi Delta Blues Festival no ano de 2015. Fonte: autor.

Como forma de obter apoio financeiro, o evento busca parcerias com instituições privadas que em troca podem se utilizar de espaços destinados para a montagem de estandes de exposição para divulgarem suas marcas. Alguns destes parceiros proporcionam experiências diferenciadas ao público, como na edição de 
2015, onde em um dos espaços localizava-se em salão de beleza com profissionais que ofereciam de forma gratuita penteados e maquiagens inspirados na cultura do blues.

Analisando o festival em números, tendo como base a edição de 2014, o evento contou com a participação de mais de 10.500 pessoas ao longo de três noites, com o auxílio de aproximadamente 500 funcionários. Neste ano, ocorreram 78 apresentações em 6 palcos distintos, 11 workshops e, visando a sustentabilidade, foram distribuídos 13.000 copos comemorativos (MDBF, 2015a). Estes números explicitam a importância do festival na questão de participação das pessoas, geração de trabalhos temporários, possibilidades de experiências e movimentação da economia da cidade, além de atrair turistas.

\section{CONSIDERAÇÕES FINAIS}

Eventos culturais como o Mississippi Delta Blues Festival são de grande importância para as cidades, tornando-as mais criativas, pois criam um cenário de múltiplas possibilidades sensoriais e permitem às pessoas novas experiências territoriais através das apresentações, shows, gastronomia e de toda a aura cultural inerente a eventos desta tipologia. Assim, a participação da população é uma questão importante para o sucesso de um evento e para o desenvolvimento de uma cidade que deseja posicionar-se criativamente. Para isso, as pessoas devem se sentir parte integrante das iniciativas, ou seja, se identificar com as propostas, para que possam interagir, promover encontros e ampliar ideias e discussões.

Neste sentido, os agentes iniciais de uma mudança ou de novas ideias devem ser claros, objetivos em suas intenções, buscando atender às expectativas das pessoas para que o resultado seja positivo. E, no outro lado do sistema, as pessoas envolvidas devem participar de forma efetiva para que as ideias se propaguem e se ampliem, reforçando o argumento sustentado por MARTINS (2011, p. 80), que destaca a importância de uma relação harmoniosa entre quem tem a força das ideias e quem tem o poder das forças para promover e gerar ambientes criativos.

Eventos, das mais diversas tipologias, são desafiados a unir os três principais elementos de uma cidade criativa: inovação, conexão e cultura. No caso do Mississippi Delta Blues Festival, este atende ao quesito cultural por se tratar de um evento que abrange arte, educação e entretenimento trazendo benefício econômico à cidade. Além disso, atende à questão de inovação por ser um modelo criativo voltado para uso da sociedade e, para que o evento possa ocorrer, diversas conexões são formadas e se estendem durante as edições e depois delas.

Este artigo buscou o entendimento da importância de eventos, com foco no Mississippi Delta Blues Festival, no contexto de cidade criativa, buscando a compreensão de características presentes neste tipo de atividade. É possível concluir que o Mississippi Delta Blues Festival é um evento que permite a vivência e a experimentação de seu público e contribui para a formação de uma cidade criativa. Ainda assim, com base nos estudos de caso, conclui-se também que há a possibilidade de ampliação e melhoria do evento para que este possa colaborar de forma extensiva para a cidade de Caxias do Sul - RS, não apenas durante as edições, como também em outros momentos, viabilizando ainda mais o desenvolvimento criativo da cidade. 


\section{REFERÊNCIAS}

AURÉLIO. Criatividade. Disponível em: http://dicionariodoaurelio.com/criatividade.

Acesso em: 20 dez. 2015.

CHICAGO, City of. Chicago Blues Festival. Disponível em:

http://www.cityofchicago.org/city/en/depts/dca/supp_info/chicago_blues_festival.ht ml. Acesso em: 21 dez. 2015a.

CHICAGO, Choose. Festivais. Disponível em:

http://www.choosechicago.com/articles/view/CHICAGO-FESTIVALS/1446/. Acesso em: 21 dez. 2015b.

CHICAGO, Choose. Chicago Blues Festival. Disponível em:

http://www.choosechicago.com/chicago-blues-festival/. Acesso em: 21 dez. 2015c.

CHICAGO, City of. A História do Blues nas Escolas. Disponível em:

http://www.cityofchicago.org/city/en/depts/dca/supp_info/chicago_blues_festival2.ht ml. Acesso em: 21 dez. 2015d.

FESUPPO. Guia de Caxias do Sul. Disponível em:

http://www.guiadecaxiasdosul.com/pagina_esp/visualizar/97\#.VnixFfkrJdh. Acesso em: 22 dez. 2015.

KAGEYAMA, Peter. Cidade Criativa. In: REIS, Ana Carla Fonseca; KAGEYAMA, Peter (Org.). Cidades criativas: perspectivas. São Paulo: Garimpo de Soluções, 2011.

MARTINS, Rolando Borges. Lisboa, Criativa? In: REIS, Ana Carla Fonseca; KAGEYAMA, Peter (Org.). Cidades criativas: perspectivas. São Paulo: Garimpo de Soluções, 2011.

MDBF. Histórico. Disponível em: http://www.mdbf.com.br/. Acesso em: 21 dez. 2015a․

MDBF. Novidades. Disponível em:

http://www.mdbf.com.br/index2.php?link=novidades\&id=11. Acesso em: $21 \mathrm{dez}$. 2015b.

MSDELTA. História. Disponível em: http://www.msdelta.com.br/historia_blues.php. Acesso em: 21 dez. 2015a.

MSDELTA. O Mississippi. Disponível em: http://www.msdelta.com.br/. Acesso em: 21 dez. $2015 b$

OSTRAS, Rio das. Histórico. Disponível em: http://www.riodasostrasjazzeblues.com. Acesso em: 27 dez. 2015a.

OSTRAS, Rio das. Palcos. Disponível em: http://www.riodasostrasjazzeblues.com. Acesso em: 27 dez. 2015b.

OSTRAS, Rio das. Festival 2015. Disponível em:

http://www.riodasostrasjazzeblues.com. Acesso em: 27 dez. 2015c.

PARDO, Jordi. Gestão e Governança nas Cidades Criativas. In: REIS, Ana Carla Fonseca; KAGEYAMA, Peter (Org.). Cidades criativas: perspectivas. São Paulo: Garimpo de Soluções, 2011. 
REIS, Ana Carla Fonseca. Cidades criativas: soluções inventivas: o papel da copa, das olimpíadas e dos museus internacionais. São Paulo: Garimpo de Soluções; Recife: FUNDARPE, 2010.

REIS, Ana Carla Fonseca; KAGEYAMA, Peter (Org.). Cidades criativas: perspectivas. São Paulo: Garimpo de Soluções, 2011.

STRICKLAND, Bill. Cidade Criativa. In: REIS, Ana Carla Fonseca; KAGEYAMA, Peter (Org.). Cidades criativas: perspectivas. São Paulo: Garimpo de Soluções, 2011.

VERHAGEN, Evert. Qualidade Líquida de Cidade. In: REIS, Ana Carla Fonseca; KAGEYAMA, Peter (Org.). Cidades criativas: perspectivas. São Paulo: Garimpo de Soluções, 2011. 